\title{
Pigmented Villonodular Synovitis of the Ankle
}

\author{
Wei-Ting Lin ${ }^{1,2}$, Shun-Chien Cheng ${ }^{1}$, Chung-Da Wu ${ }^{1}$, Shin-Sung Chiang ${ }^{3}$, \\ Chia-Yang Hong ${ }^{4}$ and Chien-Ming Chao ${ }^{5,6}$
}

Key words: arthralgia, pigmented villonodular synovitis

(Intern Med 52: 1149-1150, 2013)

(DOI: 10.2169/internalmedicine.52.0075)

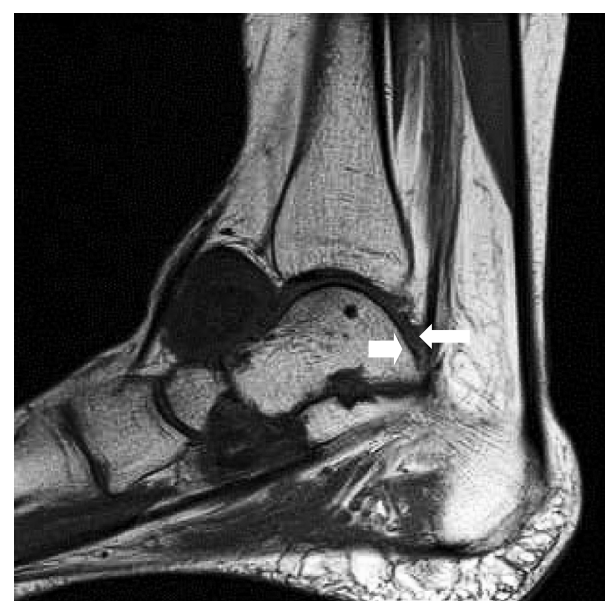

Picture 1.

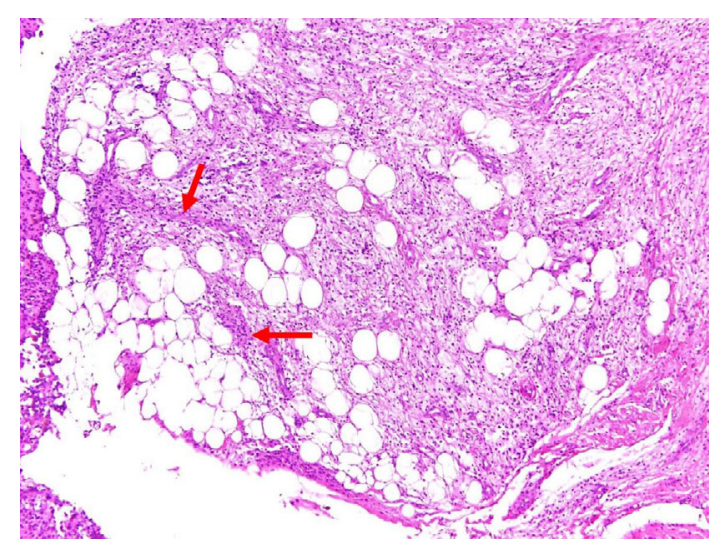

Picture 3.

A 24-year-old woman presented with painful swelling of the left ankle lasting for several months. She denied any his-

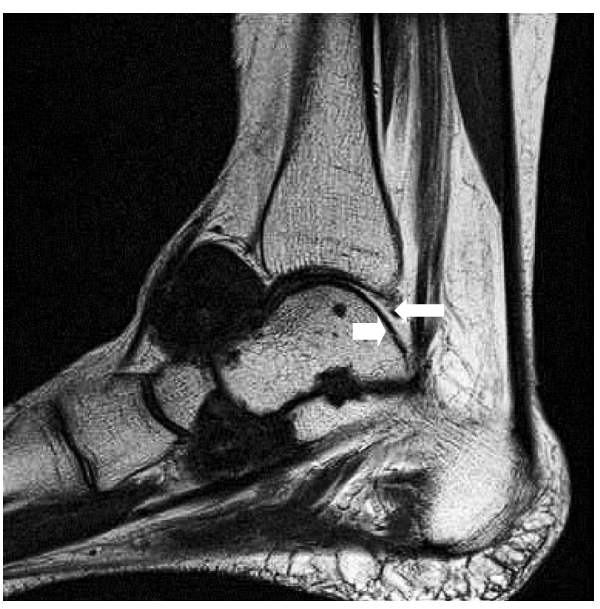

Picture 2.

tory of prior trauma or surgery. Her level of C-reactive protein was $2.4 \mathrm{mg} / \mathrm{L}$ (normal reference $<6 \mathrm{mg} / \mathrm{L}$ ). Plain radiographs showed an area of soft tissue density in the anteromedial aspect of the left ankle joint. Magnetic resonance imaging (MRI) revealed a $3.4 \times 2.3 \times 3.7-\mathrm{cm}$ soft tissue lesion in the anterior aspect of the ankle with compression and displacement of the extensor digitorum longus and the extensor hallucis longus. The lesion exhibited dark T1 and T2 signals (Pictures 1,2), intermediate to low signals on fat-saturated proton density-weighted images and heterogeneous enhancement following gadolinium administration. Under suspicion of a diagnosis of pigmented villonodular synovitis (PVNS) of the intertarsal joint, the patient underwent extensive excision of the tumor. Pathologic examinations confirmed the diagnosis of PVNS. The histopathology (Picture 3) demonstrated a diffuse-type giant cell tumor with a nodular appearance and an infiltrative border into the adipose tissue (red

\footnotetext{
${ }^{1}$ Department of Orthopaedics, Chi Mei Medical Center, Taiwan, ${ }^{2}$ Department of Physical Therapy, Shu-Zen College of Medicine and Management, Taiwan, ${ }^{3}$ Department of Pathology, Chi Mei Medical Center, Taiwan, ${ }^{4}$ Department of Radiology, Chi Mei Medical Center, Taiwan, ${ }^{5}$ Department of Intensive Care Medicine, Chi Mei Medical Center, Taiwan and ${ }^{6}$ Department of Nursing, Min-Hwei College of Health Care Management, Taiwan

Received for publication January 8, 2013; Accepted for publication February 3, 2013

Correspondence to Dr. Chien-Ming Chao, ccm870958@yahoo.com.tw
} 
arrow), which confirmed the diagnosis of PVNS.

PVNS is a benign proliferative growth of the synovium (1). As in our case, MRI provides specific findings of PVNS, which exhibits predominant hypointensity on all pulse sequences (2). This is in contrast to rheumatoid arthritis and other types of inflamed synovium, which demonstrate high signal intensity on T2-weighted MRI images.

The authors state that they have no Conflict of Interest (COI).

\section{References}

1. Mankin H, Trahan C, Hornicek F. Pigmented villonodular synovitis of joints. J Surg Oncol 103: 386-389, 2011.

2. Hao DP, Zhang JZ, Xu WJ, Wang ZC, Wang XN. Pigmented villonodular synovitis of the ankle: radiologic characteristics. J Am Podiatr Med Assoc 101: 252-258, 2011.

(C) 2013 The Japanese Society of Internal Medicine http://www.naika.or.jp/imonline/index.html 